\title{
Developing a Toolkit to Game Design
}

\author{
The Gamers4Nature Project: from Concept to Artefact
}

Pedro Beça
Pepartment of Communication and
Art, University of Aveiro, Aveiro,
Portugal
pedrobeca@ua.pt
Rita Santos
Department of Communication and
Art, University of Aveiro, Aveiro,
Portugal
rita.santos@ua.pt
Gonçalo Gomes
Department of Communication and
Art, University of Aveiro, Aveiro,
Portugal
goncalo@ua.pt

\section{ABSTRACT}

In a context where the involvement of youngers in the development of games is seen as an effective way to promote a deeper identification and engagement with the educational content, the Gamers4Nature project introduces a Toolkit designed to support youngsters in the creation of mobile digital games addressing environmental and biodiversity preservation. The Gamers4Nature Toolkit to Game Design includes a set of resources developed to support younger audiences in the creation of digital games: a Game Construction Cards Set, a Rapid Game Design Document and thematic cards, presented in a cardboard box. This paper reports on the methodological approach used for the design and evaluation of the Toolkit to Game Design. All resources were developed following a participatory design approach, with experts $(n=18)$ and potential end-users $(n=83)$ involved in the design and evaluation process. Preliminary results indicate that the Toolkit to Game Design is seen as an engaging and useful approach to game creation, able to be

This work is licensed under a Creative Commons Attribution-NoDerivs International 4.0 License.

FDG '20, September 15-18, 2020, Bugibba, Malta

(c) 2020 Copyright held by the owner/author(s).

ACM ISBN 978-1-4503-8807-8/20/09.

https://doi.org/10.1145/3402942.3402983

\author{
Ana Isabel Veloso \\ Department of Communication and \\ Art, University of Aveiro, Aveiro, \\ Portugal \\ aiv@ua.pt
}

\section{Sofia Jervis}

Bioliving, Department Biology, University of Aveiro, Aveiro, Portugal sofiajervis.bioliving@gmail.com

\section{Mariana Pereira}

Department of Communication \& Art, University of Aveiro, Aveiro, Portugal marianagomespereira@ua.pt

\footnotetext{
Department of Communication and

Portugal

saribeiro@ua.pt
} \\ Sofia Ribeiro \\ Portugal \\ a.pt
} activities.

\section{CCS CONCEPTS}

- Human-centered computing; • Interaction design; • Interaction design process and methods; - Interface design prototyping;

\section{KEYWORDS}

Toolkit, Game Design, Digital Games, Environmental Awareness, Participatory Design, Prototyping, Evaluation

\section{ACM Reference Format:}

Pedro Beça ${ }^{\dagger}$, Mónica Aresta, Ana Isabel Veloso, Rita Santos, Eduardo Ferreira, Sofia Jervis, Gonçalo Gomes, Cláudia Ortet, Mariana Pereira, and Sofia Ribeiro. 2020. Developing a Toolkit to Game Design: The Gamers4Nature Project: from Concept to Artefact. In International Conference on the Foundations of Digital Games (FDG '20), September 15-18, 2020, Bugibba, Malta. ACM, New York, NY, USA, 8 pages. https://doi.org/10.1145/3402942.3402983

\section{INTRODUCTION}

Involving students in the creation of digital games may increase the interest towards the addressed theme and make them more conscious about the value of what is learned. Along the game design process, they acquire the scientific concepts and develop digital literacy needed to create the game [1]. Nevertheless, research also points out that the lack of skills related with programming and 
game mechanics, the lack of interest in the educational subject and a focus on storytelling and character development [2-4] can become obstacles in the game creation process.

When working with publics that do not have the technological skills needed to develop a game or are not familiar with the game creation process, new strategies and approaches are needed. In this line of thought, the Gamers4Nature project developed a Toolkit to Game Design, created to support younger audiences during the conceptualization of mobile digital games related with nature and biodiversity preservation.

The development of the toolkit followed a participatory design approach, with game development experts and potential users involved in the resources' design process. This paper presents the Gamers4Nature Toolkit to Game Design development and evaluation processes, and it is organized as follows: Section 2 presents an exploratory literature review focused on the concepts of "game" and "game design"; Section 3 introduces the project and the Toolkit to Game Design development and evaluation cycles. The paper ends with some considerations and potential directions for future work in section 4 .

\section{BACKGROUND}

As research suggests that challenging students to create their own educational games can promote an engagement with the addressed theme [1], it also indicates that low programming skills, lack of interest in the addressed subject and an over-attention to storytelling and characters may lead them to ignore game mechanics and even the educational content [2-4]. The following subsections present a literature review of the concepts of "game" and "game design" and related work focused on the impact of involving students in the creation of their own digital games.

\subsection{General considerations about digital games}

There are several approaches to the concept of "game" present in literature. A game is seen as the result of the human desire to play [5], "a closed, formal system that subjectively represents a subset of reality" [6]. It is a voluntary activity that takes place in a confined environment, that has rules, and where uncertainty about the result and freedom of action within the rules limit keep the player engaged [7]. Games evolve inside a previously delimited field - limited in a material or imaginary, deliberate or spontaneous way -, a temporary world with rules and tension that exists during a specific activity [8]. This relation between rules and game is established by several authors, as demonstrated by Salen and Zimmerman in their "Rules of Play" [9], while Hunicke and his colleagues [10] present a formal approach to understanding games in their MDA (i.e. Mechanics, Dynamics and Aesthetics) Framework: a lenses to understand games, where the player experience (aesthetics) emerges through interactions (dynamics) with the game rules (mechanics). Werbach and Hunter [11] revisited the MDA framework, sustaining that game elements' tools can be taken from the game's core and used in business and/or other non-game contexts by proposing the Game Element Hierarchy or DMC (i.e. Dynamics, Mechanics and Components) Pyramid Framework.

Based on a literature review, Juul $[12,13]$ describes games as being a rule-based system with negotiable consequences, where the player works in order to influence the outcome while feeling emotionally involved. Elias and his colleagues [14] and Desurvire and his colleagues [15] stress the importance of the length of playtime, number of players and heuristics in the design of games. Fullerton [16] describes games as formal systems that engage players in a regulated conflict and that resolve in an unequal outcome. To the author, a digital game has 19 formal elements (players, objectives, procedures, rules, recourses, conflicts, boundaries, outcome), dramatic elements (challenge, play, premise, characters, story, world building and dramatic arc) and works as a system with specific elements (properties, objects, behaviours and relationships). Actions, rules, goals, objects, play space and players are mentioned by Macklin and Sharp [17] as the basic elements of play design, from which limitless play experiences can emerge.

\subsection{Students as game designers}

Information and Communication Technologies development diminished the gap that for long separated game players from game creators, making it more accessible for players to create their own games.

In the research field, user-friendly programming tools such as Scratch [18] and Kodu [19] were used to stimulate young people to learn from creating games while engaging with curricular content $[2,20]$. Being involved in the design and creation of games promotes the development of technical and non-technical (soft) skills. Role-playing game's interactive features, plots and well-developed characters fostered the design of complex interactive narratives and an increase of the required computational thinking [21]. Creating digital games raised awareness, encouraged students to explore boundaries, increased collaboration and the exchange of ideas [22], raising the interest in the programming and design field, and leading to more responsibility and better attitude in group work [4]. Young people see the creation of digital games as a highly appealing activity, as they feel motivated to develop games resembling the ones that they usually play [21]. It must be stressed, however, that creating a game requires a rich and extensive set of knowledge and skills. Game designers are asked to think about end-users, the user-game interaction, and reflect on the impact their games may have in relation with other media [23]. Nonetheless, and with the worldwide mobile gaming market growing year by year (from a 76.61 billion dollars value in 2017 to an expected 90 billion in 2020 [24] the development of digital games remain a field that captures young people's interest and motivation.

\section{GAMERS4NATURE TOOLKIT TO GAME DESIGN: DEVELOPMENT AND EVALUATION}

Toolkits, because of its problem-solving features and support materials and resources, can be considered as powerful tools able to transmit valuable insights about the production of interactive artefacts, allowing faster prototyping and supporting creative design [25-27]. By allowing users to work on different solutions by reusing, combining and adapting its components, toolkits may reduce authoring time and complexity, introduce pathways for users to create new solutions, reduce the effort to build new interactive solutions and allow for replication of ideas that explore a concept [28]. 
The Gamers4Nature project aims to design and operationalize a set of strategies that encourage the active participation of the youngest audience in game creation, namely mobile games, while promoting knowledge about environmental preservation and biodiversity conservation. One of these strategies is the development of a Toolkit to Game Design, to be used by upper secondary and undergraduate students during game development sessions, either organized in schools or in Game Jam events [29, 30].

The Gamers4Nature Toolkit to Game Design comprises a Game Construction Cards Set (cards addressing several game elements and examples of its presence in games), a Rapid Game Design Document (suggestions on how to explore the Game Construction Cards) and a set of thematic cards addressing nature and environment preservation. All resources are presented in a cardboard box with information on how to use the toolkit and are available in the project's website (www.gamers4nature.pt).

The development of the Toolkit to Game Design followed a participatory design approach [31], with experts and potential endusers (upper-secondary and undergraduate students) included in the design and evaluation process and followed the iterative design method [17].

It took place between May and November 2019, over five stages: 1) definition of the Toolkit's conceptual framework; 2) development and evaluation of Game Construction Cards Set; 3) development and evaluation of the Rapid Game Design Document; 4) development and evaluation of the thematic cards; and 5) Toolkit's overall evaluation during game design sessions.

The main steps in the development process are presented in the following sections.

\subsection{Stage 1: Definition of the Toolkit's conceptual framework}

As addressed the literature review presented in section 2, game design emerges from the relation between the output of the game design development and the user's experience while playing the game. From the review, three approaches were considered as being more in line with the Toolkit to Game Design goals: Juul's [12] perspective of game as a structure evolving around its formal system, the relation between the player and the game and the relation between the game and the rest of the world [12]; Hunicke's et al. MDA framework [10]; and Fullerton's playcentric approach to game design [16].

Taking into consideration the project's target audience - i.e. upper secondary and undergraduate students who may or may not have experience in creating games - Fullerton's [16] perspective was considered as being the most adequate for the project's conceptual framework, as it presents an extensive description of several game elements and the relations between them. As this approach would benefit from further evaluation, experts and developers from the game design field were invited to discuss each element and its relations. To instigate the discussion, a set of 19 hexagonal cardboard pieces ( $3 \mathrm{~cm}$ side), one for each game element, was distributed to each participant. Each cardboard piece had on each side the element's name. The hexagonal shape allowed the connection and aggregation of elements, fostering the construction of concepts or idea maps. All cardboard pieces had the same colour and size. A tray (size: A3) with a honeycomb structure was also distributed to each participant, to be used, if needed, during the discussion (Figure 1).

Experts and developers from the game design field were invited to discuss each element and the relations between them. It was stated by all participants $(n=13)$ that both the table board and the cardboard pieces were a valuable artefact in the exploration of game design concepts, allowing for different ways to group the elements, to expand initial perspectives and to articulate different ideas. Nevertheless, they mentioned that in order to be used by a younger and less experience audience, the pieces would need to accommodate more information and therefore should be redesigned. As for the game elements to be considered for the Toolkit, it was stated by experts and developers that 4 of the 19 elements of Fullerton's (2014) approach (i.e. properties, objects, behaviours and relationships) required a deeper knowledge on game theories and game design. According to these experts and developers, those game elements emerge from the relation and interaction between all the others. Although considering them as important for gameplay and the game experience, experts believed that these would be elements that should be provided only when all other elements were understood. Therefore, these 4 elements were not included in the Toolkit.

\subsection{Stage 2: Development and evaluation of Game Construction Cards Set}

The analysis of the experts and developers inputs evidenced that, although the hexagons and the honeycomb tray set had accomplished its goals (i.e. to promote the discussion during the construction of the conceptual framework), there was a need to redesign the cardboard hexagonal pieces in order to accommodate more information about each game element. Aiming to keep non-linear and dynamic perspective on game design, a new artefact - the Game Construction Cards Set - based on the hexagonal cardboard pieces was developed.

3.2.1 Development Cycle 1. From the insights given by the experts involved in the conceptual phase and from the literature review, it was possible to link each game element to a theoretical reference addressing its meaning and examples of its use in games. 15 cards, one for each game element, were created. Each card, sized 7,14 x $10 \mathrm{~cm}$, had in the front part information regarding the element's name, a brief description of the element and the project's logo; on the back, a small contextualization about the game element and a few examples of its presence in games was presented (Figure 2). In accordance with the project's ecological concerns, all cards were printed in recycled paper, without plastic coating.

For the first evaluation cycle, 4 focus group sessions were organized: 2 with upper-secondary students $(n=11)$ and 2 with undergraduate students $(n=8)$. Upper-secondary students were students that, although attending an ICT related course, had little or none experience in developing games. Undergraduate students were students from an ICT course, with relative experience in programming games. All participants were invited by e-mail (convenience sampling) and none had previous contact with the project guidelines or goals. All ethical issues (e.g. informed consent, respect for anonymity and confidentiality) were taken into consideration. Data 

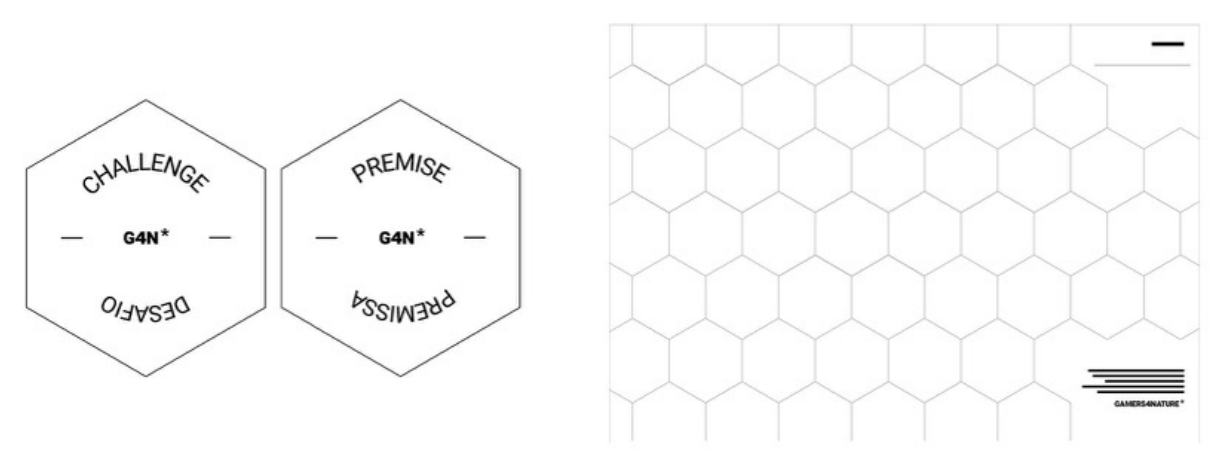

Figure 1: Hexagonal cardboard pieces and Honeycomb Table Board.

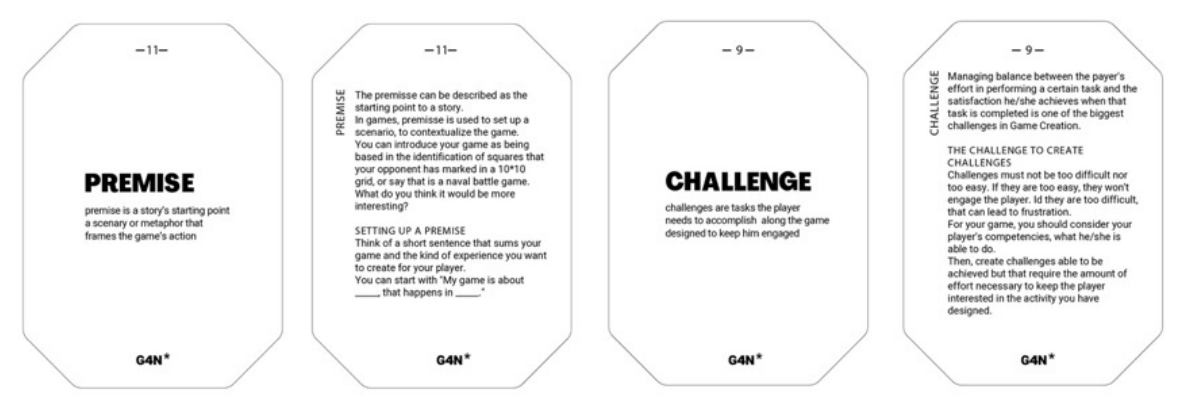

Figure 2: Premise and Challenge Game Construction Cards - Development Cycle 1.

was collected through focus groups, recorded (audio only) and later transcribed for a deeper analysis.

All focus groups started with an ice-break activity where participants were invited to talk briefly about each one's favourite game, followed by a briefly overview of the Gamers4Nature project and goals. Participants were able to discuss each card and frame it in their own game playing and game design experience: a set of Game Construction Cards was given to each one, after which they were invited to read and discuss the content of each card. Participants were asked to talk about what the element's name evoked; what could be understood from the brief description presented in the front; and to share their opinions about the information present in the back side of each card. Questions addressing the cards' design were also placed.

The analysis of information obtained from the focus groups evidenced the existence of similarities in the participants' discourse (e.g. when discussing the "rules" card, both target-groups explained this game element by using "What we can and cannot do"). This information was used to redesign the cards in the second Development Cycle of the Game Construction Cards Set.

3.2.2 Development Cycle 2. Taking into consideration the inputs collected during Development Cycle 1 and aiming to make the exploration of the cards more attractive and engaging, a "trigger question" was added to the front of each card (e.g. to the "Premise" element the "trigger question" was "How does the story begin?").
Minor edits were also made to the text (i.e. vocabulary and text distribution). Figure 3 displays the redesigned "premise" and "challenge" cards.

In Development Cycle 2, 10 focus groups were organized: 3 with some of the upper-secondary students that had already participated in development cycle $1(\mathrm{n}=10)$ and 7 with undergraduate students $(n=23)$. Each focus group session started with a brief introduction of the Gamers4Nature project, followed by the presentation of the redesigned Game Construction Cards Set. After it, each group was asked to conceptualize a game using the set of 15 cards.

Upper-secondary students' sessions lasted about 60 minutes. One group developed the game's narrative without any help from the observer; two groups asked for help, as they were not able to understand how to use the cards. This indicated that some guidance on how to use the cards set would be needed.

As for the undergraduate students' sessions, it lasted from $30 \mathrm{~min}$ utes (3 groups) from an hour and a half (4 groups). All groups developed the game's narrative with no help or explanations from the observer. By the end of the sessions, when asked to talk about how they used the cards, two groups mentioned that some elements could be grouped into a single card (e.g. premise and story). Three groups pointed out that two of the trigger questions were similar ("play - what makes the player stay?" and "challenge - how to keep the player interested?") and should be redefined.

Undergraduate students mentioned that the question by itself, along with the brief description, was enough to understand what was 


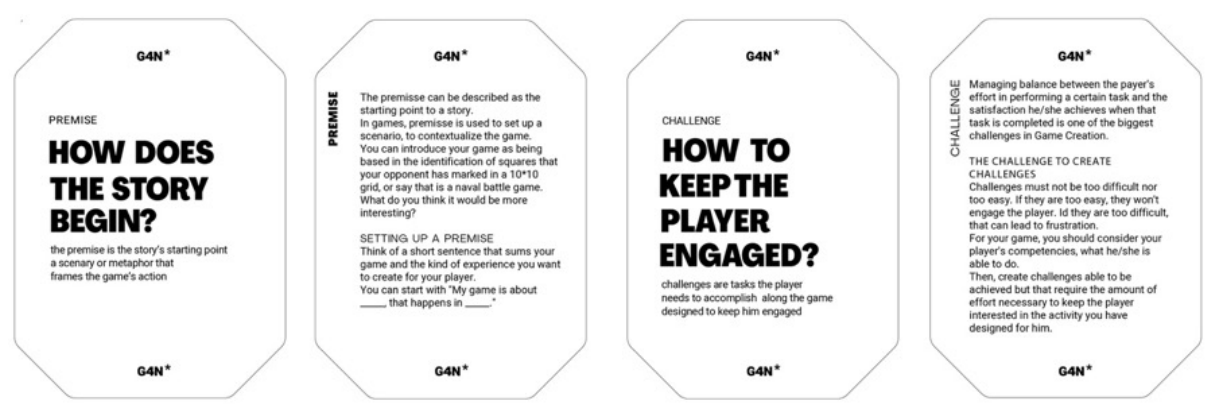

Figure 3: Premise and Challenge Game Construction Cards - Development Cycle 2.

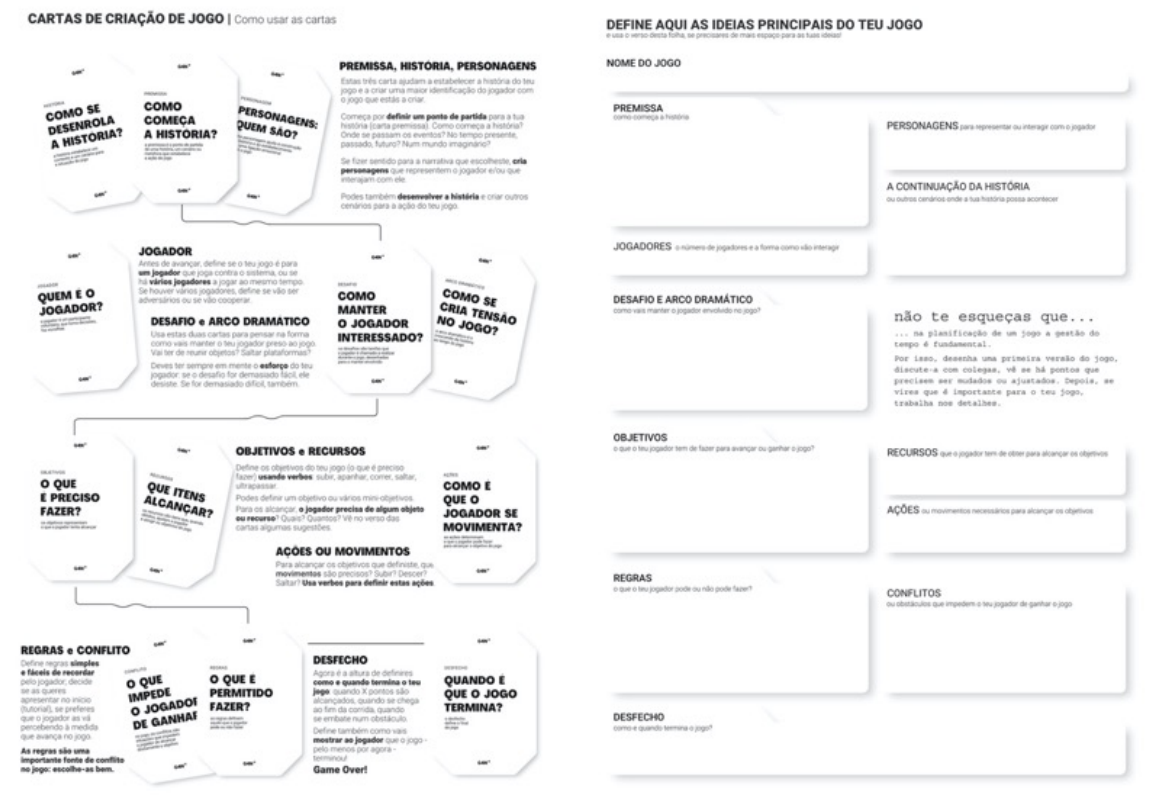

Figure 4: G4N Rapid Game Design Document.

supposed to be addressed; that the Game Construction Cards Set was useful for conceptualizing the game; and considered the informal discourse adopted in the texts as being clear and objective, making it easier to understand and process the information. Nevertheless, they stated that in order to build a game, additional tools (related with software) would be needed. It was also pointed out that the world building (trigger question: "the sky is the limit") and boundaries (trigger question: "what separates the game from the real world?") cards were not clear. As a result, these cards were discarded and the Game Construction Cards Set was formed by 12 cards.

\subsection{Stage 3: development and evaluation of the Rapid Game Design Document}

After the cards set development and evaluation cycles it was evident that, although most groups were able to set up a game's narrative by using the cards, not everyone knew how to work with the cards. Therefore, an instruction guide was needed. Game design documents and frameworks are used as guides to the game creation process, addressing dimensions such as characters and narrative, plot, mechanics, monetization, marketing, identifying and analysing the important design choices while keeping the whole picture in mind [32, 33]. The Gamers4Nature Rapid Game Design Document (Figure 4) was designed taking into consideration the participants' input, presenting a path to explore the Game Construction Cards Set and the relations between the different game elements.

The Rapid Game Design Document, printed in the A3 format, was developed in order to explain in a more detailed way the how-to construct a game narrative while using the cards set. The document evokes a game table board where the users can write while brainstorming and planning the game that is being built. At the back of the document, quotes from relevant authors of the game design field were added. 

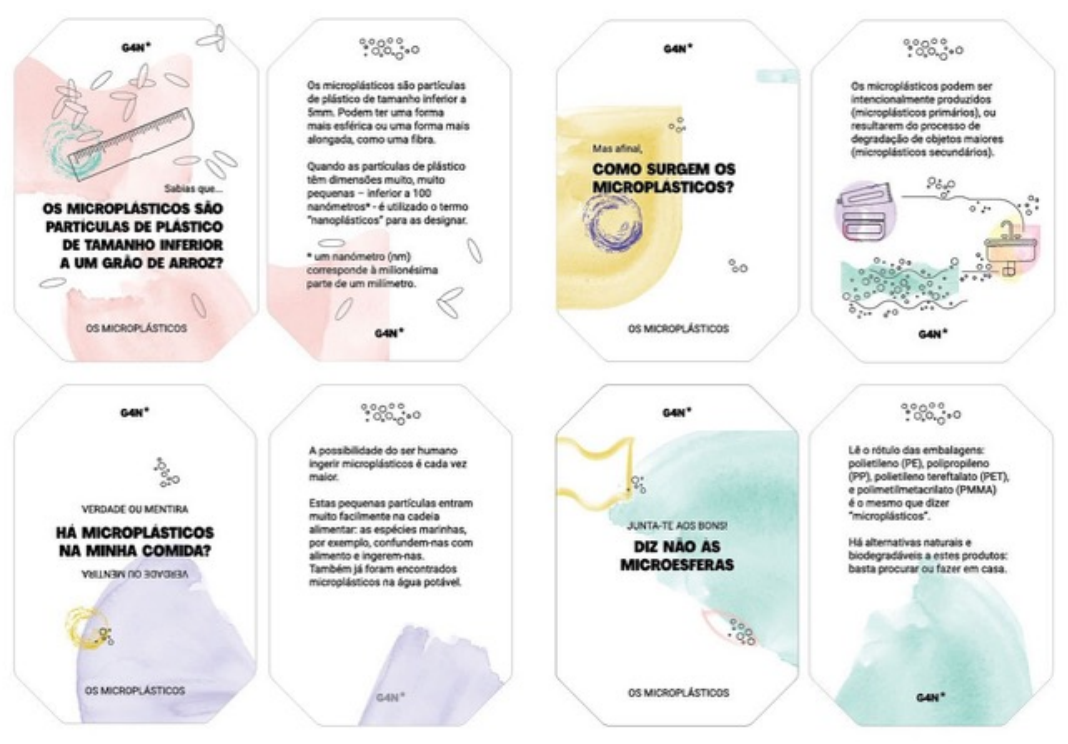

Figure 5: Example of Each Category of the Thematic Cards Set..

3.3.1 Evaluation. The Rapid Game Design Document was validated during game narrative design sessions, held with undergraduate students $(n=52)$ from ICT related and no-related courses. Along those sessions, participants used the document to outline a game's narrative. As participants considered that the Rapid Game Design Document accomplished its goal (i.e. to suggest them how to use the game construction cards in order to design a game's narrative), no suggestions of changes or improvements were made.

\subsection{Stage 4: development and evaluation of the thematic cards set}

In order to assist the construction of the game's narrative within a theme that addressed the Gamers4Nature goals (i.e. to support youngsters in the creation of mobile digital games addressing environmental and biodiversity preservation), resources focused on environmental preservation were developed. Following the "trigger question" approach taken for the Game Construction Cards Set, the topics addressed in those resources were presented as questions, along with a brief explanation of the addressed concept. As the Gamers4Nature focus on digital game creation for biodiversity and nature preservation awareness, the theme selected for the first set of thematic cards was pollution by microplastics.

20 thematic cards, sized 7,14×10cm and printed in colour, were produced. As for the content, it was organized in four categories: "did you know", addressing objective information and characteristics of microplastics (cards' base colour: pink); "but after all, ...", focused on how microplastics are created and discarded and the impact of biodiversity loss (cards' base colour: yellow); "truth or lie", fact checks on truths and myths about microplastic pollution and endangered species (cards' base colour: purple); and "take action", with simple and easy suggestions and insights able to help people to change habits and behaviours (cards' base colour: green). The graphic layout of the cards did not differ from the Game Construction Cards Set, but in order to clarify more some of the concepts addressed in the texts, illustrations were added to the front and back of the cards (Figure 5). All content (i.e. trigger question in the front, explanation in the back) was produced by biologists.

3.4.1 Evaluation. The thematic cards were validated by experts in science didactics $(n=3)$ and design $(n=2)$, and by undergraduate students from a Design course $(n=16)$. Science didactics evaluation focused on the scientific accuracy of the presented content and on the discourses' adequacy considering the project's target audience (i.e. upper-secondary and undergraduate students). Experts explored the thematic cards one at the time, suggesting minor amends to the texts. As a result of these evaluation sessions, minor edits were suggested to the content in order to make it more understandable and scientifically accurate (e.g. "it is believed that" was changed to "research suggests that"). Design experts explored the thematic cards by looking at the overall picture (i.e. grouped the cards according to their base colour, looked for consistency and balance, typos, and illustration's adequacy) and considered the overall design appealing, mentioned that both colours and illustrations were adequate, and that the font size allowed for an easy reading. As for design students, they pointed out that the card's shape, colours, and the overall concept were interesting; still, they mentioned the fact that some cards presented too much written information.

\subsection{Stage 5: Toolkit's overall evaluation during game design sessions}

The Game Construction Cards Set, the Rapid Game Design Document and the thematic cards were used and validated by undergraduate students from ICT related and non-related courses during 2 game narrative design sessions. In these sessions, participants 


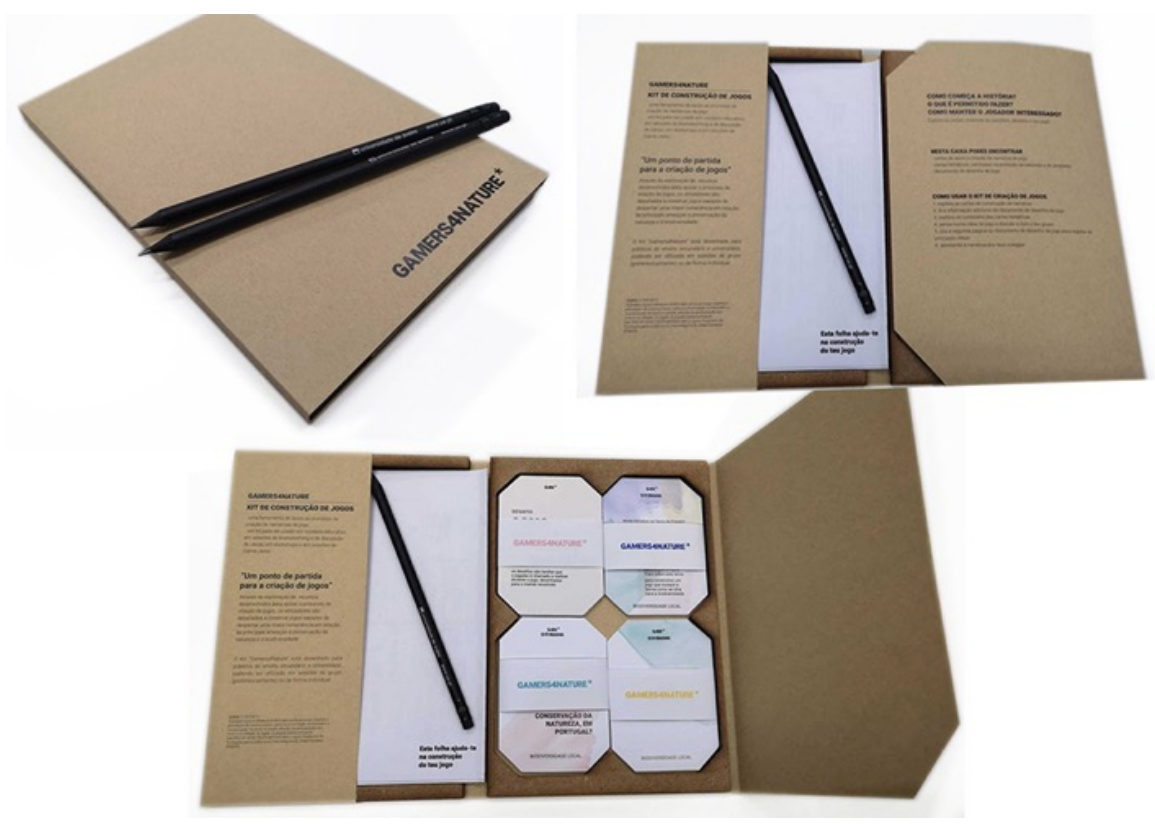

Figure 6: Gamers4Nature Toolkit to Game Design.

were challenged to use the Toolkit to develop a narrative of a game focused on microplastic pollution.

52 undergraduate students participated in the game narrative creation sessions: 6 were students from ICT courses with relative experience in programming games and 46 were student from a Social Sciences course, with no experience in developing games. During the sessions - 2 hours per session, 16 groups, 3 to 4 students per group - participants explored the game construction cards using the Rapid Game Design Document as a guide. After reading the thematic cards information and engaging in a short brainstorm session, participants structured the game narrative by following the document's path. From these sessions, 16 game narratives emerged. Participants mentioned that the Toolkit was "a funny way to learn more about the environment, it's easy to follow". The easy reading of all resources and the support given by the Rapid Game Design Document were mentioned as being the most positive aspects. Nevertheless, the overload of information ("There are too many thematic cards") was mentioned by five users as the Toolkit's major weakness. Further details of this evaluation stage will be presented on a paper to be published.

The Toolkit was also used in real game design sessions with uppersecondary students. Along these sessions, and by using the Toolkit, students were able to develop a prototype (first levels) of a playable digital game addressing environmental and nature preservation, showing that it achieved its purpose: to support young students during the game design process. Results can be found in [34].

\subsection{Additional resources: packaging and project's website}

In order to accommodate all the Toolkit's resources and to ease its transportation to the Game Design sessions, a specific packaging was developed. Paper bags or boxes were considered as a solution; however, they lacked elegance and coherence with the Toolkit's resources. Other important aspect was the need to develop a resource as much sustainable as possible, without the use of plastic.

After several attempts - that included a cardboard folder and a more complex structure, also in cardboard, but with several glued elements that required too much time and precision - a first prototype of the Toolkit to Game Design box was developed.

Made in cardboard and MDF (i.e. Medium Density Fibreboard), the box allows for the accommodation of all Toolkit's resources, keeping them in place even when the box is moved from one place to another. Similar to a book cover, the cardboard structure wraps the MDF structure and presents instructions on how to use the toolkit (Figure 6). This approach made the Toolkit simple and easy to be used in classes' context or even other game creation events.

All resources and editable templates are available in the Gamers4Nature website (www.gamers4nature.pt), to be downloaded and adapted to other scenarios. The project's website introduces the Gamers4Nature project, the downloadable Toolkit, and it will be used also as repository for the mobile digital games created by youngsters during game design sessions.

\section{CONCLUSIONS}

When working with audiences that are not familiar with the game creation process or do not have the required technological skills to develop a game, toolkits may reduce authoring time and complexity, ease the decision-making process and enable new audiences to build interactive solutions (Ledo, et al., 2018). By allowing users to create different solutions by engaging with and adapting the pieces, blocks or elements provided by the toolkit, Toolkits can be seen as an interesting support to the game creation process.

This paper described the Gamers4Nature Toolkit to Game Design development and evaluation process. The development followed 
a participatory design approach with experts and potential endusers included in the design and evaluation process and took place between May and November 2019. Experts from the game design field $(n=13)$, from science didactics $(n=3)$ and design $(n=2)$, design students $(\mathrm{n}=16)$ and potential end-users (upper-secondary students, $\mathrm{n}=11$, and undergraduate students, $\mathrm{n}=83$ ) were involved in the development and evaluation of the Toolkit's resources.

Along with the Game Construction Cards Set, the Rapid Game Design Document, the thematic cards and even the packaging, the Gamers4Nature Toolkit to Game Design was able to provide its users a set of predefined educational resources addressing an environmental awareness theme, assisting them in their narrative and storytelling development. Nevertheless, a few limitations should be considered for this research: the selection of the participants (i.e. experts and students) invited to discuss and validate the Toolkit's artefacts was made through convenience sampling, not allowing for the generalization of these results. Moreover, the insufficient sample size of upper-secondary students and their involvement in the two Game Construction Cards Set development cycles may have influenced participant's perspectives about the readability and adequacy of the information added to the cards. As for undergraduate students, the discrepancy between the number of ICT and non-ICT students does not allow for comparisons between the outputs of each group's game narrative design sessions.

The team has already had the opportunity to use the Toolkit in real game design sessions with upper-secondary students, showing that it achieved its purpose: to support young students during the game design process. In the next stage of the project, the Toolkit will be introduced to a wider audience, through game creation sessions organized with upper-secondary and undergraduate students and Game Jam events. Additional thematic cards sets, addressing environmental awareness and biodiversity preservation issues are being developed and validated through the same methodological approach described in this paper.

The results presented in this paper make it possible to expect that the Gamers4Nature Toolkit to Game Design will represent an important contribution to the promotion of environmental awareness within younger audiences. It is also expected that the promotion of game design activities may contribute to foster the development of soft skills such as the ability to work in teams, creativity and the ability to solve problems, skills that are increasingly valued in society.

\section{ACKNOWLEDGMENTS}

This work is part of the Gamers4Nature project, PTDC/COMOUT $/ 31047 / 2017$, that has the financial support of FCT-Foundation for Science and Technology (Portugal)/MCTES - Ministry of Science, Technology and Higher Education and FEDER under the PT2020 agreement.

Eduardo Ferreira is funded by national funds (OE), through FCTFoundation for Science and Technology, I.P., in the scope of the framework contract foreseen in the numbers 4, 5 and 6 of the art. 23, of the Decree-Law 57/2016, of August 29, changed by Law 57/2017, of July 19.

\section{REFERENCES}

[1] J. Huizenga, G. ten Dam, J. Voogt and W. Admiraal. 2017. Teacher perceptions of the value of game-based learning in secondary education. Computers\&Education, no. 110 , pp. $105-115$

[2] F. Ke. 2014. An implementation of design-based learning through creating educational computer games: A case study on mathematics learning during design and computing. Computers \& Education, vol. 73, pp. 26-39.

[3] K. Howland and J. Good. 2015. Learning to communicate computationally with Flip: A bi-modal programming language for game creation. Computers \& Education, vol. 80, pp. 224-240.

[4] T. P. Falcão, F. M. d. A. e. Peres, D. C. S. d. Morais and G. d. S. Oliveira. 2018. Participatory methodologies to promote student engagement in the development of educational digital games. Computers in Human Behaviour, vol. 116, pp. 161-175.

[5] E. Adams. 2014. Fundamentals of Game Design (3rd ed.), Thousand Oaks, CA: New Riders Publishing.

[6] C. Crawford. 1984. The Art of Computer Game Design, New York: McGraw-Hill, Inc.

[7] R. Callois. 1990. Os jogos e os homens: a máscara e a vertigem- Trad fosé Garcez Palha, Cotovia, Ed., Lisboa.

[8] J. Huizinga. 2001. Homo Ludends, S. Perspectiva, Ed., São Paulo.

[9] K. Salen and E. Zimmerman. 2004. Rules of Play: Game Design Fundamentals.

[10] R. Hunicke, M. Leblanc and R. Zubec. 2004. MDA: A Formal Approach to Game Design and Game Research. in AAAI Workshop on Challenges in Game AI, 2004.

[11] K. Werbach and D. Hunter. 2012. For the Win: How Game Thinking Can Revolutionize Your Business, Wharton Digital Pe.

[12] J. Juul. 2003. The Game, the Player, the World: Looking for a Heart of Gameness. in Level Up: Digital Games Research Conference Proceedings, 2003.

[13] J. Juul. 2005. Half-Real: Video Games between Real Rules and Fictional Worlds, Cambridge: MIT Press.

[14] G. S. Elias, R. Garfield and K. R. Gutschera. 2012. Characteristics of Games, The MIT press.

[15] H. Desurvire, M. Caplan and J. A. Toth. 2004. Using Heuristics to Evaluate the Playability of Games. in Extended Abstracts of the 2004 Conference on Human Factors \& Computing Systems - CHI 04.

[16] T. Fullerton. 2014. Game Design Workshop: a playcentric approach to creating innovative games (3rd ed.), Taylor \& Francis Group.

[17] C. Macklin and J. Sharp. 2016. Games, Design and Play: a detailed approach to Iterative Game Design, Addison-Wesley.

[18] M. M. Lab, Scratch [computer program], MIT MEdia Lab.

[19] M. Research, Kodu [computer software]

[20] K. Øygardslia and P. Aarsand. 2018. "Move over, I will find Jerusalem": Artifacts in game design in classrooms. Learning, Culture and Social Interaction, vol. 19, pp. 61-73.

[21] J. Good and K. Howland, 2017. Programming language, natural language? Supporting the diverse computational activities of novice programmers. Journal of Virual Languages and Computing, vol. 39, pp. 78-92.

[22] M. N. Giannakos and L. Jaccheri. 2018. From players to makers: An empirical examination of factors that affect creative game development. International Journal of Child-Computer Interaction, no. 18, pp. 27-36.

[23] K. Salen. 2007. Gaming Literacies: A Game Design Study in Action. Journal of Educational Multimedia and Hypermedia, vol. 16, no. 3, pp. 301-322.

[24] WePC. 2020. "2020 Video Game Industry Statistics, Trends \& Data,".

[25] J. Wobbrock, A. Wilson and Y. Li. 2007. Gestures without libraries, toolkits or training: a $\$ 1$ recognizer for user interface prototypes. in Proceedings of the 20th annual ACM symposium on User interface software and technology.

[26] S. Greenberg. 2007. Toolkits and interface creativity. Multimedia Tools and Applications, vol. 32, pp. 139-159.

[27] A. Oulasvirta and K. Hornbæk. 2016. HCI Research as Problem-Solving. in CHI '16: Proceedings of the 2016 CHI Conference on Human Factors in Computing Systems.

[28] D. Ledo, S. Houben, J. Vermeulen, N. Marquardt, L. Oehlberg and S. Greenberg. 2018. Evaluation Strategies for HCI Toolkit Research. in Proceedings of the 2018 CHI Conference on Human Factors in Computing Systems - CHI 18.

[29] A. Kultima. 2015. Defining GAme Jam. in 10th International Conference on the Foundations of Digital Games.

[30] K. D. Myerscough, R. Eberhardt, M. Jakobsson and C. Lo. 2017. Jamming for Allies: Finding a Formula for Inclusive Design Exploration Collaborations. in Proceedings of the Second International Conference on Game Jams, Hackathons, and Game Creation Events.

[31] C. Spinuzzi. 2005. The Methodology of Participatory Design. Technical Communication - Applied Research, vol. 52, no. 2, pp. 163-174.

[32] B. Roungas. 2016. Towards the validation of a simulation environment. in Winter Simulation Conference (WSC), Washington DC, IEEE, pp. 3676-3677.

[33] K. Mikami, Y. Nakamura, A. Ito, M. Kawashima, T. Watanabe, Y. Kishimoto and K. Kondo. 2016. Effectiveness of Game Jam-based iterative program for game production in Japan. in Computers \& Graphics, pp. 1-10.

[34] P. Beça, M. Aresta, C. Ortet, R. Santos, A. Veloso and S. Ribeiro. 2020. Promoting student engagement in the design of digital games The creation of games using a Toolkit to Game Design. in20th IEEE International Conference on Advanced Learning Technologies (ICALT 2020), Estonia. 